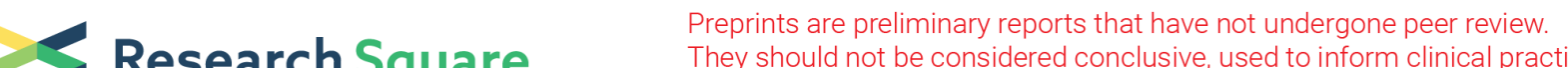 Research Square
or referenced by the media as validated information.
}

\section{Recombinant PAL/PilE/FlaA DNA vaccine provides protective immunity against Legionella pneumophila in BALB/c mice}

\section{Yingying Chen}

Shengjing Hospital of China Medical University

\section{Zehui Yang}

Shengjing Hospital of China Medical University

\section{Ying Dong}

Shengjing Hospital of China Medical University

Yu Chen ( $\nabla$ chenyusy@hotmail.com )

Shengjing Hospital of China Medical University https://orcid.org/0000-0001-6835-3804

\section{Research article}

Keywords: Legionella pneumophila, DNA vaccine, PAL, PilE, FlaA

Posted Date: February 10th, 2020

DOI: https://doi.org/10.21203/rs.2.23041/v1

License: (9) This work is licensed under a Creative Commons Attribution 4.0 International License.

Read Full License

Version of Record: A version of this preprint was published at BMC Biotechnology on May 18th, 2020. See the published version at https://doi.org/10.1186/s12896-020-00620-3. 


\section{Abstract}

Background: Legionella pneumophila (L.pneumophila), a Gram-negative small microorganism, causes hospital-acquired pneumonia especially in immunocompromised patients. Vaccination may be an effective method for preventing L.pneumophila infection. Therefore, it is necessary to develop a better vaccine against this disease. In this study, we developed a recombinant peptidoglycan-associated lipoprotein (PAL)/type IV pilin (PilE)/lagellin (FlaA) DNA vaccine and evaluated its immunogenicity and efficacy to protect against L.pneumophila infection.

Results: According to the results, the expression of PAL, PilE, FlaA proteins and PAL/PilE/FlaA fusion protein in 293 cells was confirmed. Immunization with PAL/PilE/FlaA DNA vaccine resulted in highest IgG titer and strongest cytotoxic T-lymphocyte (CTL) response. Furthermore, the histopathological changes in lung tissues of mice challenged with a lethal dose of L.pneumophila were alleviated by PAL/PilE/FlaA DNA vaccine immunization. The production of T-helper-1 (Th1) cytokines (IFNY, TGF-a, and IL-12), and Th2 cytokines (IL-4 and IL-10) were promoted in PAL/PiIE/FlaA DNA vaccine group. Finally, immunized with PAL/PilE/FlaA vaccine raised the survival rate of mice to $100 \%$ after challenged with a lethal dose of L.pneumophila for 10 consecutive days.

Conclusions: Our study suggests that the newly developed PAL/PilE/FlaA DNA vaccine stimulates strong humoral and cellular immune responses and may be a potential intervention of L.pneumophila infection.

\section{Background}

Legionella pneumophila (L.pneumophila) is a Gram-negative small microorganism, widely found in nature and man-made water systems[1,2]. The sporadic, epidemic, or hospital infection of L.pneumophila can be fatal, especially in immunocompromised patients $[3,4]$. If the patients do not receive timely and correct diagnosis and treatment, the mortality rate of L.pneumophila infection can be as high as $50 \%[5]$. Currently, there is no effective measure to prevent L.pneumophila infection. Therefore, developing effective, safe vaccine with no toxic side effects to fight L.pneumophila infection is of significance.

Early research found that animals artificially infected with L.pneumophila could generate a humoral or cell mediated immune response[6, 7]. In addition, compared with the mono-antigen vaccine, the recombinant multi-antigen vaccine has been proven to better induce immunogenicity and stimulate protective immune response [8, 9]. L.pneumophila contains multiple virulence factors, such as peptidoglycan-associated lipoprotein (PAL), lagellin (FlaA), and type IV pilin (PilE). PAL is a $19 \mathrm{kDa}$ outer membrane lipoprotein, and as a species distinctive immunodominant component, can be served as a diagnostic indicator for L.pneumophila infection[10]. FlaA protein is a key component of L.pneumophila flagella. The flagella can enhance the invasion ability of bacteria, which promotes the infection to host cells[11]. Moreover, study suggested that FlaA could play crucial roles in the protective immunity against lethal dose infection of L.pneumophila in mice via stimulating T-cell-mediated immune reaction[12]. PilE 
protein has been demonstrated to facilitate the adhesion between bacteria and their host cells, and is closely related to the DNA transformation of L.pneumophila[13]. So far, the effect of recombinant PAL/PilE/FlaA vaccine against L.pneumophila infection has not been determined.

Thus, in the present study we selected PAL, PilE, and FlaA for candidates to construct new recombinant DNA vaccine and investigated its immunogenicity and protective efficacy against L.pneumophila in mice.

\section{Results}

\section{Construction of recombinant plasmids and expression of recombinant proteins in 293T cells}

The full-length gene sequences of PAL, PilE, and FlaA were synthesized and separately cloned into the pcDNA3.1 vector to generate recombinant plasmids of pcPAL, pcPilE, pcFlaA, and pcPAL/PilE/FlaA for expressing PAL, PilE, FlaA, or the fusion protein of PAL/PilE/FlaA, respectively. To verify the expression of these proteins in eukaryotic cells, these recombinant plasmids were transfected into 293 cells. As shown in Fig. 1B, the result of western blotting confirmed the expression of PilE (about $15 \mathrm{kDa}$ ), PAL (about $19 \mathrm{kDa}$ ), FlaA (about $34 \mathrm{kDa}$ ), and PAL/PilE/FlaA (about $70 \mathrm{kDa}$ ).

\section{DNA vaccines induced humoral immune in mice}

To assess the recombinant DNA vaccines-induced humoral immune response in mice, the IgG titers were detected by ELISA. As presented in Fig. 2, the IgG titers were gradually increased from 1 week to 5 weeks after the enhanced immunization, which were greatly declined at 7 weeks after the enhanced immunization. Among all these recombinant DNA vaccines, the IgG titer in these groups from high to low, in turn, is PAL/PilE/FlaA, PAL, PilE and FlaA. In the pcDNA3.1 group, the lgG titer was undetectable. So these results suggested that DNA vaccine PcPAL/PilE/FlaA induced a stronger humoral immune response in mice.

\section{DNA vaccines induced $C T L$ response in mice}

The spleen lymphocytes were isolated from mice to determine CTL response. As assessed by MTT assay and shown in Fig. 3, compared with pcDNA3.1 group, the CTL response was stronger in PAL, PilE, FlaA, and PAL/PilE/FlaA groups. Among these recombinant DNA vaccine groups, PAL/PilE/FlaA group showed strongest CTL response.

\section{Immunization with recombinant PAL/PilE/FlaA DNA vaccine protected mice against L.pneumophila challenge}

To further investigate PAL/PilE/FlaA DNA vaccine-induced protective immunity in mice, the histopathological changes in lung tissues of mice that challenged with a lethal dose of L.pneumophila 
were observed by HE staining. As illustrated in Fig. 4, there was significant inflammatory cell infiltration and destruction of alveolar tissue in the lung tissues of L.pneumophila-infected mice. However, in the lung tissues of mice immunized with PAL/PilE/FlaA DNA vaccine, the inflammatory cell infiltration was obviously restrained. Moreover, the cytokine response was determined by ELISA. As presented in Fig. 5A$\mathrm{C}$, the serum levels of TNF- $\mathrm{a}$, IFNy, and IL-10 were significantly up-regulated in PAL/PilE/FlaA group, as compared with control or pcDNA3.1 groups. In the supernatant of splenocyte cultures of mice challenged with a lethal dose of L.pneumophila, the levels of TNF-a, IFNy, IL-12, IL-4 and IL-10 were remarkably enhanced in PAL/PilE/FlaA group after culture for 12, 24, 48, and $72 \mathrm{~h}$ (Fig. 6A-E). The survival rate of mice after infected with L.pneumophila was monitored for 10 consecutive days. As shown in Fig. 7, the survival rate of mice immunized with PAL/PilE/FlaA DNA vaccine was $100 \%$ up to 10 days after infection with L.pneumophila; whereas, there were no living mice in control and pcDNA3.1 non-immunized groups from 1 day to 10 days. All the above results indicated that PAL/PilE/FlaA DNA vaccine played an efficient role to prevent L.pneumophila infection in mice.

\section{Discussion}

In this study, we developed a recombinant PAL/PilE/FlaA DNA vaccine to protect against L.pneumophila infection in mice. The results suggested that immunization with recombinant PAL/PilE/FlaA DNA vaccine successfully induced humoral and cellular immunity, alleviated lung inflammation and enhanced the survival rate of L.pneumophila-challenged mice.

Recombinant DNA vaccine provides the possibility for production of antigen protein with high purity, which may replace inactivated vaccine and attenuated live vaccine because of its high security and easy production features. The recombinant protein produced by Escherichia coli can not exactly reflect the native structure of bacterial protein, so it is not ideal to evaluate protective efficacy of recombinant protein vaccine in rabbits[14]. After immunization with DNA vaccine, the endogenous antigen protein with natural conformation can be produced by cells within the body, which induces humoral and cellular immunity just like pathogen infection[15]. Compared with recombinant protein vaccine, the titer of produced high affinity antibody is 100-1000 times higher after injection of DNA vaccine[16]. Therefore, compared with traditional vaccines, DNA vaccine has the characteristics of strong and long immune responses, and no virulence reversion. A previous study has indicated that pcDip/pilE DNA vaccine is effective to protect against L.pneumophila infection[17]. In our study, we constructed a new DNA vaccine with three protective antigens and evaluated its immune effects.

Gene synthesis is an effective method to obtain DNA template[18]. Gene synthesis is also used to construct DNA vaccine, which avoids the culture of pathogens and lowers the risk for pathogen infection. Chen et al synthesized the optimized coding sequence of CHA5 to build CHA5 DNA vaccine that induced broad protection against H5N1 influenza viruses[19]. In a recent study, the cDNA sequences encoding fulllength Ebola GP and VP40 were synthesized to construct DNA vaccine, which induced specific humoral and cellular immune responses in mice[20]. In this study, the cDNA sequences of PAL, PilE, and FlaA were synthesized and cloned into pcDNA3.1 vector. The expression of PAL, PilE, FlaA proteins and 
PAL/PilE/FlaA fusion protein were confirmed in 293 cells transfected with recombinant plasmids, which provided a good foundation for the ongoing study.

The ideal vaccine should be an efficient inducer of both humoral and cellular immune responses. To observe the humoral immune responses induced by these recombinant DNA vaccines, we performed ELISA to detect the titer of specific IgG antibody after three times of immunization. According to our results, immunization with PAL, PilE, FlaA and PAL/PilE/FlaA recombinant DNA vaccines could significantly enhance the IgG titer. The results also suggested that PAL/PilE/FlaA recombinant DNA vaccine proved the most obvious effect. The strong CTL response demonstrated that the PAL, PilE, and FlaA proteins played pivotal roles in antigen presentation and subsequent induction of cellular immune response. Our results indicated that the CTL response was strongest in PAL/PilE/FlaA recombinant DNA vaccine group, compared to that in PAL, PilE, or FlaA group. All these results proved that PAL/PilE/FlaA recombinant DNA vaccine could induce higher humoral and cellular immune responses, so we next evaluated the protective immunity of PAL/PilE/FlaA DNA vaccine against a lethal challenge with L.pneumophila.

Helper T cell cytokines are a kind of mediators that have extensively biological activities. T-helper-1 (Th1) cell derived cytokines such as IFNy, TGF-a, and IL-12 promote the synthesis of IgG2a, and enhance CTL response, which play crucial roles in cellular immune response. While Th2 cell cytokines such as IL-4 and IL-10 contribute to B cell proliferation and IgG1 synthesis, which mainly induce humoral immune response[21]. The balance between Th1 and Th2 cytokines maintains immune homeostasis. The type of immune responses and efficacy of vaccines can be evaluated through the detection of secreted cytokines after vaccination $[22,23]$. In the present study, we detected the levels of Th1 cytokines IFNy, TGF-a, and IL-12, and Th2 cytokines IL-4 and IL-10 at $16 \mathrm{~h}$ after L.pneumophila infection. We found that the serum levels of TNF-a, IFNy, IL-10 were increased, and in the supernatant of splenocytes the levels of TNF-a, IFNy, IL-12, IL-4 and IL-10 were remarkably enhanced after immunization with PAL/PilE/FlaA DNA vaccine. Thus, PAL/PilE/FlaA DNA vaccine elicited both Th1 and Th2 immune responses in mice. Moreover, the survival and histopathological changes in lung tissues of mice were improved by immunization with PAL/PilE/FlaA vaccine. Therefore, protective immunity was induced by PAL/PilE/FlaA DNA vaccine against L.pneumophila infection in mice.

There is a lot of debate on the security of DNA vaccine. The primary one is that the vector DNA may integrate into the host genome. However, a lot of research has shown that the integration rate of vector DNA is lower than that of host genome spontaneous mutation [24-26]. In addition, the inoculation methods may affect the safety of DNA vaccine. It has been demonstrated that intramuscular injection and gene gun bombardment are safe inoculation methods for DNA vaccine [27-30]. Based on these studies, the risk of PAL/PilE/FlaA vector integration into host genome was considered to be very low. Although no poisonous side effect was observed in mice after injection of DNA vaccine, the possibility of $\mathrm{PAL} / \mathrm{PilE} / \mathrm{FlaA}$ vector integration into the host genome may exist, which was not assessed in this work. In our subsequent study, we will focus on this issue. 


\section{Conclusion}

Recombinant PAL/PiIE/FlaA DNA vaccine shows higher potential to induce both humoral and cellular immune responses compared with each comprising protein and effectively protects against L.pneumophila infection in mice.

\section{Methods}

\section{Animals}

Six-to-eight-week-old female BALB/c mice (weight about $20 \mathrm{~g}$ ) were purchased from Liaoning changsheng biotechnology co. Ltd. The mice were housed under a specific pathogen free condition at 22 $\pm 1{ }^{\circ} \mathrm{C}$, humidity of $45-55 \%$, and a $12 \mathrm{~h}$ light/dark cycle, with free access to food and water.

\section{Bacterial strains, media and growth conditions}

Bacteria of L. pneumophila serogroup 1 (American Type Culture Collection, USA; no. 35133) were cultured on buffered charcoal-yeast extract agar with buffered charcoal yeast extract (BCYE) (Merck, Germany) in a candle urn at $37^{\circ} \mathrm{C}$ with humidified atmosphere and collected with phosphate buffered saline (PBS). After being washed in sterile PBS and centrifuged at $4{ }^{\circ} \mathrm{C}$, the bacteria were diluted to the proper concentration.

\section{DNA vaccine construction and expression in mammalian cells}

The cDNA sequences encoding full-length PAL (Gene ID: 19833609), PilE (Gene ID: 19833480), and FlaA (Gene ID: 19832905) antigens were synthesized by Sangon Biotech Co., Ltd (Shanghai, China) and were cloned into the corresponding sites of the eukaryotic expression vector pcDNA3.1 (Invitrogen, Carlsbad, USA). The obtained recombinant plasmids, named as pcPAL, pcPilE, pcFlaA, and pcPAL/PilE/FlaA, respectively, were identified by DNA sequencing. The plasmid profile for pcPAL/PilE/FlaA is shown in Fig. 1A.

293 cells were purchased from Zhong Qiao Xin Zhou Biotechnology Co., Ltd (RZQ0002, Shanghai, China) and were maintained in minimum essential medium (MEM, Gibco, USA) containing $10 \%$ fetal bovine serum (Hyclone, USA) at $37{ }^{\circ} \mathrm{C}$ under $5.0 \% \mathrm{CO}_{2}$ atmosphere. 293 cells were transfected with the recombinant plasmids pcPAL, pcPilE, pcFlaA, and pcPAL/PilE/FlaA, respectively, by using lipofectamine 2000 (Invitrogen, USA) according to the manufacturer's instructions. After transfection for $72 \mathrm{~h}$, the protein expression was detected by western blotting as described below.

\section{Western blotting}

293 cells were lysed in RIPA (Solarbio, China) containing 1 mM PMSF (Solarbio). The protein concentration was evaluated by BCA Protein Assay Kit (Solarbio). Subsequently, $20 \mu \mathrm{g}$ protein sample was subjected to sodium dodecyl sulfate polyacrylamide gel electrophoresis and transferred to 
polyvinylidene difluoride membranes (Millipore, USA). After being blocked with $5 \%$ skimmed milk, the membranes were incubated with Rabbit anti-L.pneumophila polyclonal antibody (1:500, MyBioSource, USA) at $4{ }^{\circ} \mathrm{C}$ overnight. Then the membranes were incubated with Goat Anti-rabbit IgG/HRP antibody (1:3000, Solarbio) at $37^{\circ} \mathrm{C}$ for $1 \mathrm{~h}$. The bands were visualized by ECL solution (Solarbio).

\section{Immunization of mice}

The BALB/c mice were randomly divided into five groups ( $n=6$ per group, total 30 ), separately immunized by pcDNA3.1, pcPAL, pcPilE, pcFlaA, and pcPAL/PilE/FlaA. Briefly, the mice were intramuscularly injected with $50 \mu \mathrm{g}$ pcDNA3.1, $50 \mu \mathrm{g}$ pcPAL, $50 \mu \mathrm{g}$ pcPilE, $50 \mu \mathrm{g}$ pcFlaA, and $50 \mu \mathrm{g}$ pcPAL/PilE/FlaA, respectively. Two weeks and four weeks after the immunization, the mice were injected with the above DNA vaccines at the same dose to enhance immunization. At 1, 3, 5, and 7 weeks after the enhanced immunization, the serum samples were collected and stored at $-70^{\circ} \mathrm{C}$. The mice were euthanized by an overdose of pentobarbital sodium (200 mg/kg, i.p.), and the spleen lymphocytes were isolated from mice at 7 weeks after the enhanced immunization for further experiments.

\section{Antibody detection}

The total immunoglobulin $\mathrm{G}(\mathrm{IgG})$ titers were determined by indirect enzyme-linked immunosorbent assay (ELISA). Briefly, the 96-well plates were coated with $100 \mu \mathrm{l}$ recombinant PAL/PilE/FlaA antigen at $4{ }^{\circ} \mathrm{C}$ overnight. After being washed in PBST buffer for three times, the plates were blocked in 5\% skimmed milk at $37^{\circ} \mathrm{C}$ for $2 \mathrm{~h}$. Then $100 \mu \mathrm{l}$ serial dilutions of serum samples were added to each well and incubation at $37^{\circ} \mathrm{C}$ for $1 \mathrm{~h}$. Then the plates were washed in PBST buffer for three times and incubated with HRPlabeled Goat Anti-Mouse IgG $\left(1: 250\right.$, Beyotime, China) at $37^{\circ} \mathrm{C}$ for $1 \mathrm{~h}$. The plates were then incubated with $200 \mu \mathrm{l} \mathrm{TMB}$ Chromogen Solution (Beyotime) at $37^{\circ} \mathrm{C}$ for $20 \mathrm{~min}$ in the dark. To terminate the reaction, $50 \mu \mathrm{l}$ of $2 \mathrm{M} \mathrm{H} 2 \mathrm{SO} 4$ was added to each well. The results were detected at $450 \mathrm{~nm}$ by a microplate reader (BioTek, USA).

\section{Measurement of the cytotoxic T-lymphocyte (CTL) response}

To assess CTL response, the isolated spleen lymphocytes $\left(5 \times 10^{6} / \mathrm{ml}\right.$, effector cells) from immunized mice were mixed with the cells expressing PAL, PilE, FlaA, and PAL/PilE/FlaA ( $5 \times 10^{5} / \mathrm{ml}$, target cells), respectively, and then seeded into 96-well plates. The single cultured spleen lymphocytes or PAL, PilE, FlaA, and PAL/PilE/FlaA positive expressing cells were used as effector control or target control. After culture for $56 \mathrm{~h}$, the cells in each group were incubated with $0.5 \mathrm{mg} / \mathrm{ml}$ methyl-thiazolyl-tetrazolium (MTT) at $37^{\circ} \mathrm{C}$ for $4 \mathrm{~h}$. After discarding the supernatant, each well was added with $150 \mu \mathrm{l}$ DMSO. The absorbance at $570 \mathrm{~nm}$ was detected by a microplate reader. The CTL response was evaluated as the following formula: $C T L=\left[1-\left(A_{570}\right.\right.$ effector $-A_{570}$ effector control $\left.)\right] / A_{570 \text { target control }} \times 100 \%$.

\section{Studies of protective immunity}

The BALB/c mice were randomly divided into three groups ( $n=16$ per group, total 48 ): control group, pcDNA3.1 group, and pc PAL/PilE/FlaA group, and were intramuscularly injected with equal volume of PBS, $50 \mu \mathrm{g}$ pcDNA3.1, or $50 \mu \mathrm{g}$ pcPAL/PilE/FlaA, respectively. The mice were injected with the above DNA 
vaccines at the same dose to enhance immunization at two weeks and four weeks after the immunization. Two weeks after the enhanced immunization, the mice were intravenously injected with a lethal dose of L.pneumophila $\left(2 \times 10^{7} \mathrm{CFU}\right.$ in PBS). At $16 \mathrm{~h}$ after the injection of L.pneumophila, serum samples were collected from 6 mice in each group. Then the mice were euthanized by an overdose of pentobarbital sodium ( $200 \mathrm{mg} / \mathrm{kg}$, i.p.), and the lung tissues were removed and fixed in $4 \%$ paraformaldehyde. The spleen tissues were collected for culture of splenocytes. The remaining 10 mice in each group were monitored for another 10 days for survival analysis.

\section{Hematoxylin-eosin (HE) staining}

To observe the pathological changes of the lung tissues, HE staining was performed. The lung tissues were embedded in paraffin and cut into $5-\mu \mathrm{m}$ sections. Then the sections were subjected to routine $\mathrm{HE}$ staining. The results were observed under a light microscope (Olympus, Japan) and the images were taken at a magnification of $200 x$.

\section{Cytokine response analysis}

Cytokine levels in serum samples or the supernatants of splenocytes cultured for $12,24,48$, and $72 \mathrm{~h}$ were detected by commercial ELISA kits for TNF-a, IL-12, IFNy, IL-4, and IL-10 (USCN Business Co., Ltd, Wuhan, China), according to the manufacturer's instructions.

\section{Statistical analysis}

All results were presented as mean \pm standard deviation (SD). One-way ANOVA followed by Bonferroni's Multiple Comparison Test was performed to analyze data among different groups using GraphPad Prism 5 software. A P value less than 0.05 was considered to be statistically significant.

\section{Abbreviations}

L.pneumophila, Legionella pneumophila; PAL, peptidoglycan-associated lipoprotein; PilE, type IV pilin; FlaA, lagellin; CTL, cytotoxic T-lymphocyte; Th1, T-helper-1; BCYE, buffered charcoal yeast extract; PBS, phosphate buffered saline; MEM, minimum essential medium; IgG, immunoglobulin G; ELISA, enzymelinked immunosorbent assay; MTT, methyl-thiazolyl-tetrazolium; HE, hematoxylin-eosin; SD, standard deviation.

\section{Declarations}

\section{Ethics approval and consent to participate}

All animal experiments were conducted in accordance with international ethical guidelines and the National Institutes of Health Guide concerning the Care and Use of Laboratory Animals. The experimental protocol was approved by Shengjing Hospital of China Medical University.

\section{Consent for publication}

Not applicable. 
Availability of data and materials

The datasets used and/or analysed during the current study are available from the corresponding author on reasonable request.

\section{Competing interests}

The authors declare that they have no competing interests.

\section{Funding}

This study was supported by grants from the National Key R\&D Program of China (No. 2017YFC1309702) and the National Natural Science Foundation of China (No. 81170009). The funders contributed in the study design, data collection and analysis, writing and revising of the manuscript.

\section{Authors' contributions}

YYC and YC contributed in the conception and design of the research. YYC, ZHY, and YD contributed to acquisition, analysis, or interpretation of data. YYC wrote the manuscript. YC reviewed and edited the manuscript. All authors read, edited and approved the final version of the manuscript.

\section{Acknowledgments}

Not applicable.

\section{Author details}

Department of Pulmonary and Critical Care Medicine, Shengjing Hospital of China Medical University, Shenyang 110022, People's Republic of China.

\section{References}

1. Coscolla M, Fenollar J, Escribano I, Gonzalez-Candelas F: Legionellosis outbreak associated with asphalt paving machine, Spain, 2009. Emerg Infect Dis 2010, 16(9):1381-1387.

2. Lee HK, Shim JI, Kim HE, Yu JY, Kang YH: Distribution of Legionella species from environmental water sources of public facilities and genetic diversity of L. pneumophila serogroup 1 in South Korea. Appl Environ Microbiol 2010, 76(19):6547-6554.

3. Fields BS, Benson RF, Besser RE: Legionella and Legionnaires' disease: $\mathbf{2 5}$ years of investigation. Clin Microbiol Rev 2002, 15(3):506-526.

4. Gomez-Valero L, Rusniok C, Buchrieser C: Legionella pneumophila: population genetics, phylogeny and genomics. Infect Genet Evol 2009, 9(5):727-739.

5. Gomez-Valero L, Rusniok C, Rolando M, Neou M, Dervins-Ravault D, Demirtas J, Rouy Z, Moore RJ, Chen $\mathrm{H}$, Petty NK et al: Comparative analyses of Legionella species identifies genetic features of 
strains causing Legionnaires' disease. Genome Biol 2014, 15(11):505.

6. Blander SJ, Breiman RF, Horwitz MA: A live avirulent mutant Legionella pneumophila vaccine induces protective immunity against lethal aerosol challenge. J Clin Invest 1989, 83(3):810-815.

7. Blander SJ, Horwitz MA: Vaccination with the major secretory protein of Legionella induces humoral and cell-mediated immune responses and protective immunity across different serogroups of Legionella pneumophila and different species of Legionella. J Immunol 1991, 147(1):285-291.

8. Thera MA, Plowe CV: Vaccines for malaria: how close are we? Annu Rev Med 2012, 63:345-357.

9. Disis ML, Gad E, Herendeen DR, Lai VP, Park KH, Cecil DL, O'Meara MM, Treuting PM, Lubet RA: A multiantigen vaccine targeting neu, IGFBP-2, and IGF-IR prevents tumor progression in mice with preinvasive breast disease. Cancer Prev Res (Phila) 2013, 6(12):1273-1282.

10. Godlewska R, Wisniewska K, Pietras Z, Jagusztyn-Krynicka EK: Peptidoglycan-associated lipoprotein (Pal) of Gram-negative bacteria: function, structure, role in pathogenesis and potential application in immunoprophylaxis. FEMS Microbiol Lett 2009, 298(1):1-11.

11. Dietrich C, Heuner K, Brand BC, Hacker J, Steinert M: Flagellum of Legionella pneumophila positively affects the early phase of infection of eukaryotic host cells. Infect Immun 2001, 69(4):2116-2122.

12. Ricci ML, Torosantucci A, Scaturro M, Chiani P, Baldassarri L, Pastoris MC: Induction of protective immunity by Legionella pneumophila flagellum in an A/J mouse model. Vaccine 2005, 23(40):48114820.

13. Stone BJ, Kwaik YA: Natural competence for DNA transformation by Legionella pneumophila and its association with expression of type IV pili. J Bacteriol 1999, 181(5):1395-1402.

14. Lafond RE, Lukehart SA: Biological basis for syphilis. Clin Microbiol Rev 2006, 19(1):29-49.

15. Gurunathan S, Klinman DM, Seder RA: DNA vaccines: immunology, application, and optimization*. Annu Rev Immunol 2000, 18:927-974.

16. Boyle JS, Silva A, Brady JL, Lew AM: DNA immunization: induction of higher avidity antibody and effect of route on T cell cytotoxicity. Proc Natl Acad Sci U S A 1997, 94(26):14626-14631.

17. Xu JN, Yang ZW, Chen JP, Chen DL, Wang T, Liu MJ, Zhang L, Yang BB: Protective immunity against Legionnaires' disease in an AVJ mouse model using a DNA vaccine composed of an outer membrane protein (29 kDa) and the pilE fusion protein. Diagn Microbiol Infect Dis 2012, 73(1):9-15.

18. Beattie KL, Logsdon NJ, Anderson RS, Espinosa-Lara JM, Maldonado-Rodriguez R, Frost JD, 3rd: Gene synthesis technology: recent developments and future prospects. Biotechnol App/ Biochem 1988, 10(6):510-521.

19. Chen MW, Cheng TJ, Huang Y, Jan JT, Ma SH, Yu AL, Wong $\mathrm{CH}$, Ho DD: A consensus-hemagglutininbased DNA vaccine that protects mice against divergent H5N1 influenza viruses. Proc Natl Acad Sci U S A 2008, 105(36):13538-13543.

20. Ren S, Wei Q, Cai L, Yang X, Xing C, Tan F, Leavenworth JW, Liang S, Liu W: Alphavirus Replicon DNA Vectors Expressing Ebola GP and VP40 Antigens Induce Humoral and Cellular Immune Responses in Mice. Front Microbiol 2017, 8:2662. 
21. Mosmann TR, Sad S: The expanding universe of T-cell subsets: Th1, Th2 and more. Immunol Today 1996, 17(3):138-146.

22. Rico MA, Quiroga JA, Subira D, Castanon S, Esteban JM, Pardo M, Carreno V: Hepatitis B virusspecific T-cell proliferation and cytokine secretion in chronic hepatitis $B$ e antibody-positive patients treated with ribavirin and interferon alpha. Hepatology 2001, 33(1):295-300.

23. Vordermeier HM, Lowrie DB, Hewinson RG: Improved immunogenicity of DNA vaccination with mycobacterial HSP65 against bovine tuberculosis by protein boosting. Vet Microbio/ 2003, 93(4):349-359.

24. Brave A, Gudmundsdotter L, Sandstrom E, Haller BK, Hallengard D, Maltais AK, King AD, Stout RR, Blomberg P, Hoglund $U$ et al: Biodistribution, persistence and lack of integration of a multigene HIV vaccine delivered by needle-free intradermal injection and electroporation. Vaccine 2010, 28(51):8203-8209.

25. Doukas J, Morrow J, Bellinger D, Hilgert T, Martin T, Jones D, Mahajan R, Rusalov D, Sullivan S, Rolland A: Nonclinical biodistribution, integration, and toxicology evaluations of an H5N1 pandemic influenza plasmid DNA vaccine formulated with Vaxfectin(R). Vaccine 2011, 29(33):5443-5452.

26. Dolter KE, Evans CF, Ellefsen B, Song J, Boente-Carrera M, Vittorino R, Rosenberg TJ, Hannaman D, Vasan S: Immunogenicity, safety, biodistribution and persistence of ADVAX, a prophylactic DNA vaccine for HIV-1, delivered by in vivo electroporation. Vaccine 2011, 29(4):795-803.

27. Liu MA: DNA vaccines: an historical perspective and view to the future. Immunol Rev 2011, 239(1):62-84.

28. Glenting J, Wessels S: Ensuring safety of DNA vaccines. Microb Cell Fact 2005, 4:26.

29. Pilling AM, Harman RM, Jones SA, McCormack NA, Lavender D, Haworth R: The assessment of local tolerance, acute toxicity, and DNA biodistribution following particle-mediated delivery of a DNA vaccine to minipigs. Toxicol Pathol 2002, 30(3):298-305.

30. Wang Z, Troilo PJ, Wang X, Griffiths TG, Pacchione SJ, Barnum AB, Harper LB, Pauley CJ, Niu Z, Denisova $L$ et al: Detection of integration of plasmid DNA into host genomic DNA following intramuscular injection and electroporation. Gene Ther 2004, 11(8):711-721.

\section{Figures}


A
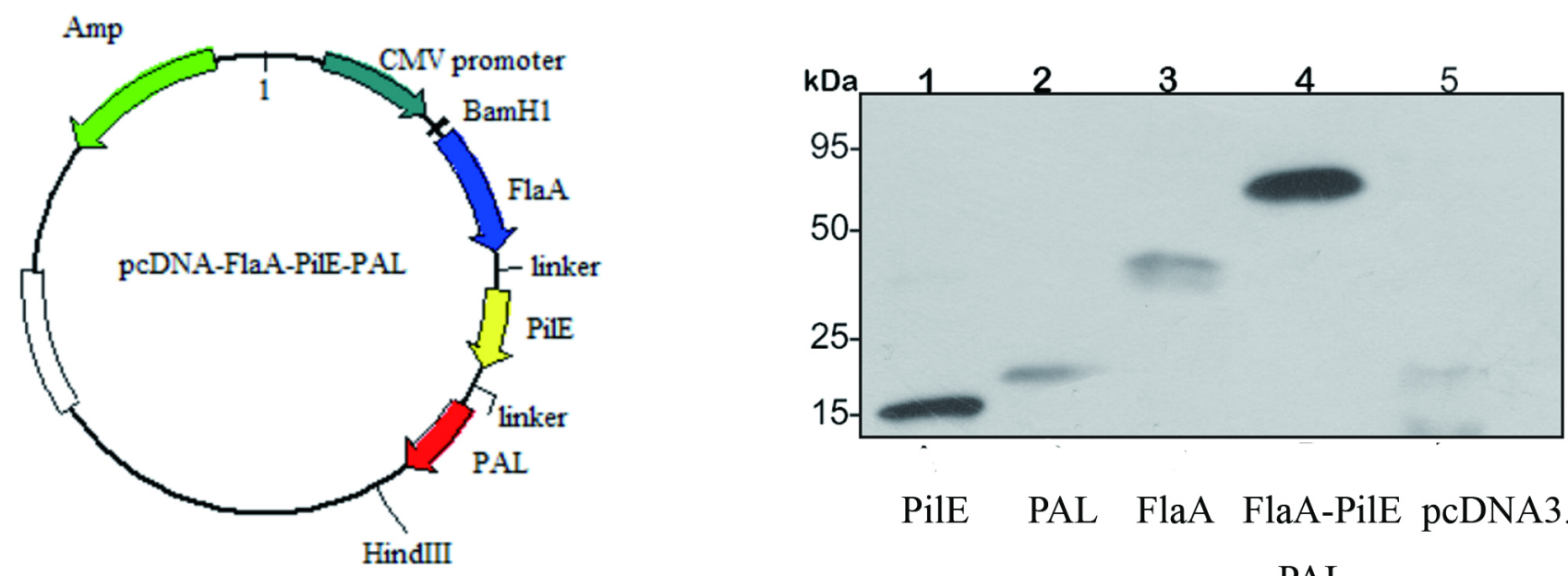

PilE PAL FlaA FlaA-PilE pcDNA3.1 $-\mathrm{PAL}$

Figure 1

Construction of recombinant expression vector and verification of recombinant protein expression in 293T cells. (A) Construction maps of recombinant pcDNA-FlaA-PilE-PAL. (B) 293T cells were transiently transfected with pcDNA-FlaA, pcDNA-PilE, pcDNA-PAL, pcDNA-FlaA-PilE-PAL or pcDNA 3.1 for $72 \mathrm{~h}$, then the cell lysates were subjected to western blot assay using rabbit Legionella pneumophila polyclonal antibody.

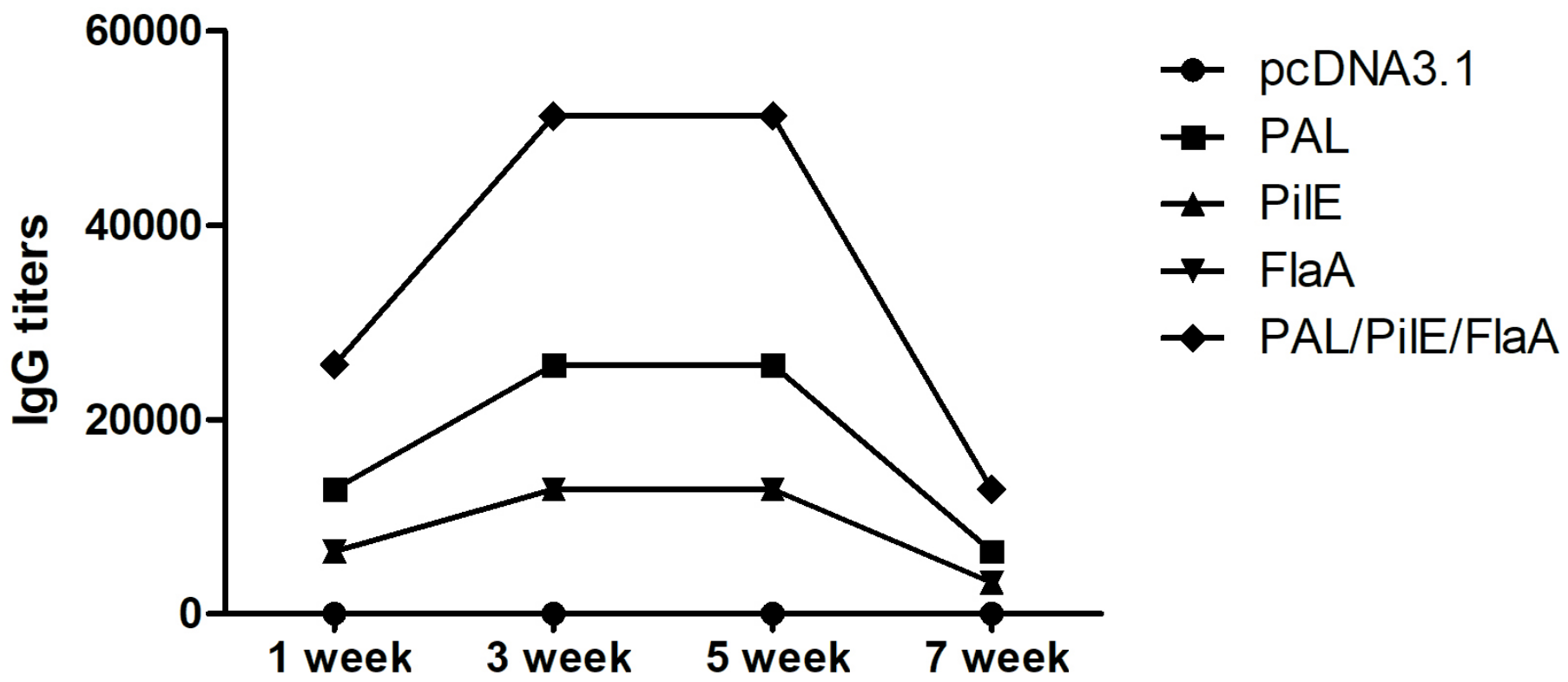

Figure 2 
Humoral immune responses of the DNA vaccines in immunized mice. $50 \mu \mathrm{g}$ of DNA vaccines were biweekly intramuscularly injected into the mice for three times. The IgG titers of multiples groups were detected by ELISA at 1, 3, 5, and 7 weeks after the last immunization.

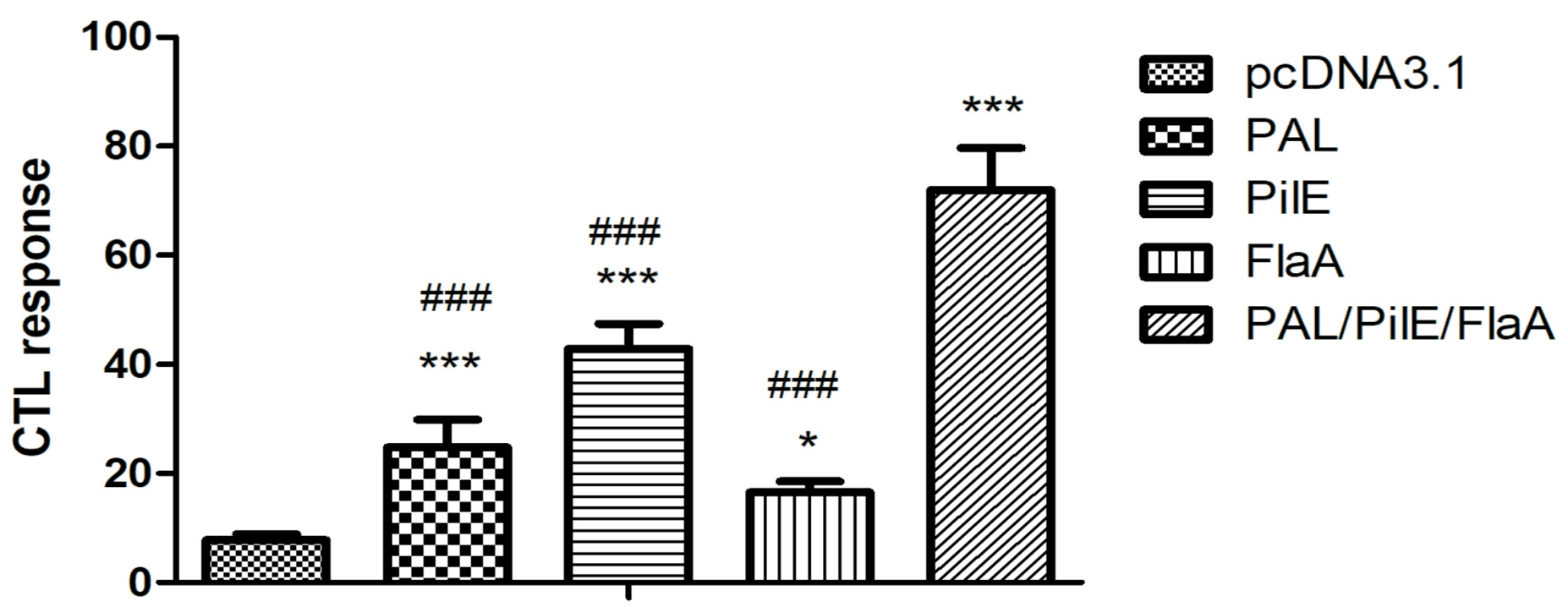

Figure 3

The cytotoxic T-lymphocyte (CTL) response in mice immunized with the DNA vaccines. At 7 weeks after the last immunization, the spleen lymphocytes were separated. The CTL response was detected by MTT assay.

L. p-control

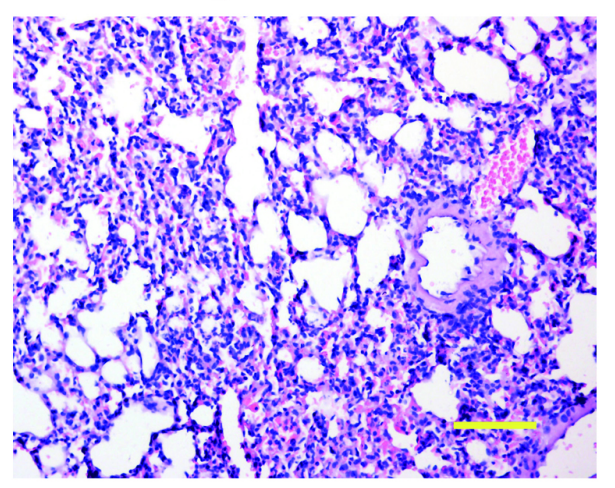

L. p-pcDNA3.1

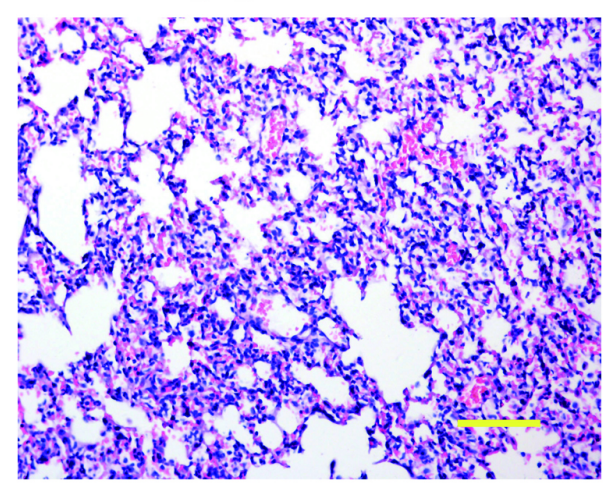

L. p-PAL/PilE/FlaA

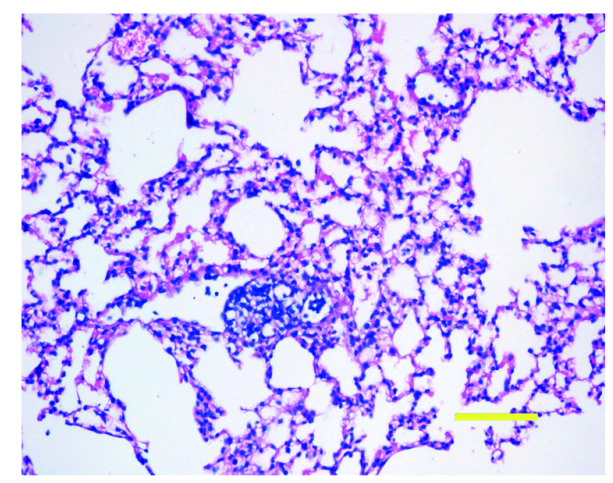

Figure 4

The histological morphologic changes of lungs in mice challenged with a lethal dose of Legionella pneumophila. The lung sections from different groups were stained with hematoxylin and eosin (HE). Scale bar $=100 \mu \mathrm{m}$. 
A
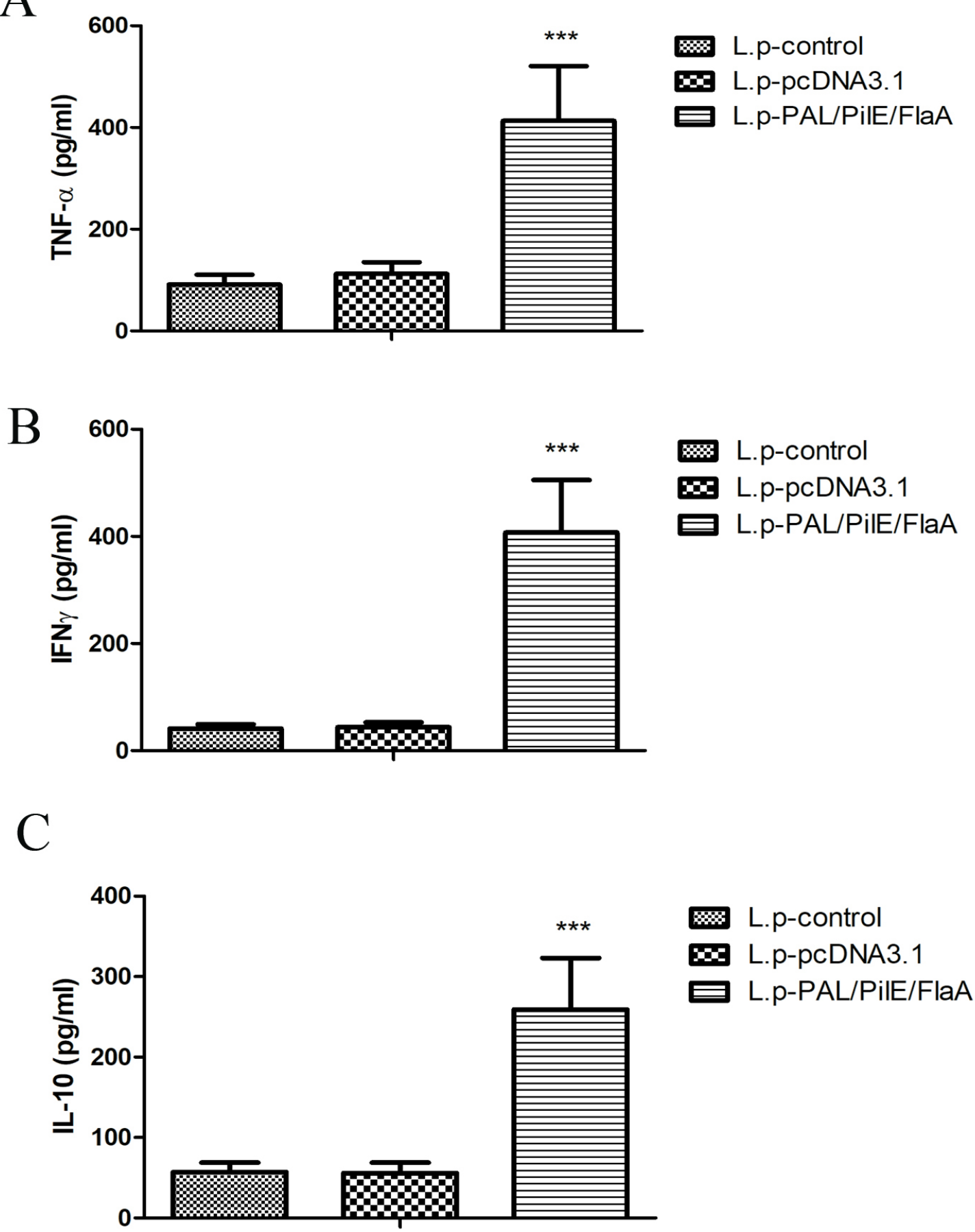

Figure 5

The cytokine levels of serum samples collected from mice at $16 \mathrm{~h}$ after a lethal challenge with Legionella pneumophila. The TNF-a (A), IFNy (B), and IL-10 (C) levels were evaluated by ELISA kits. All data were expressed as mean $\pm S D(n=6)$. ${ }^{* \star *} P<0.001$ versus the L.p-pcDNA3.1 group. 
A
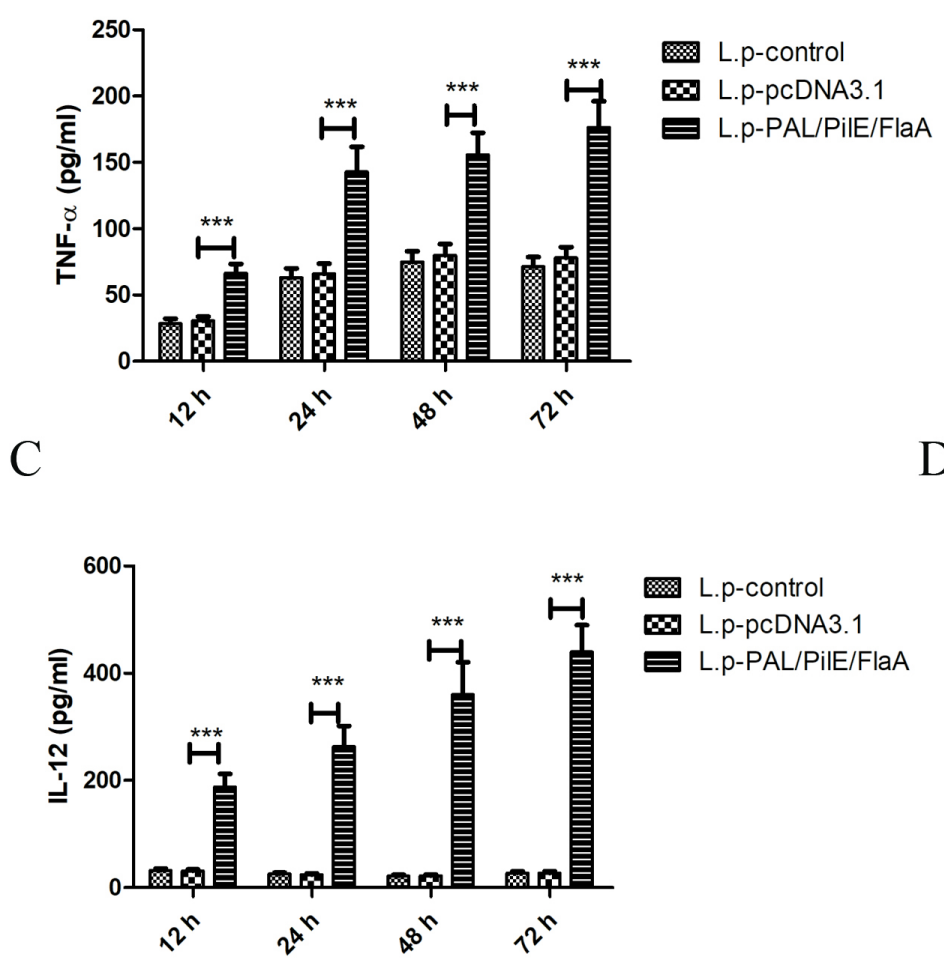

$\mathrm{E}$
B

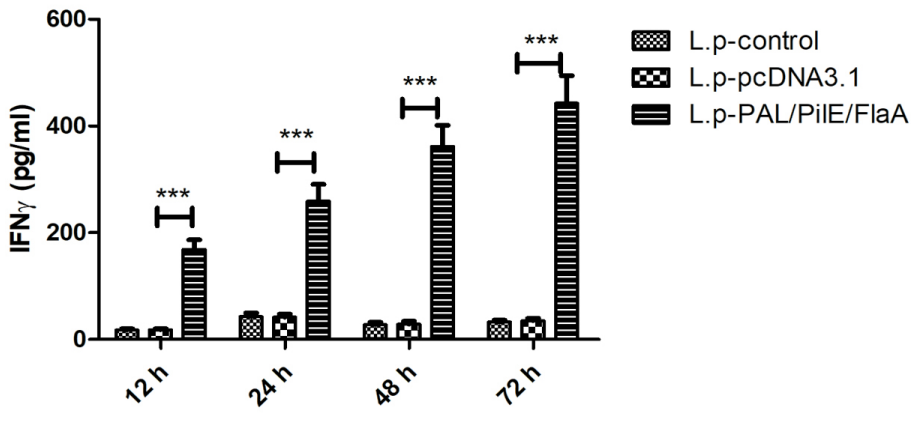

$\mathrm{D}$

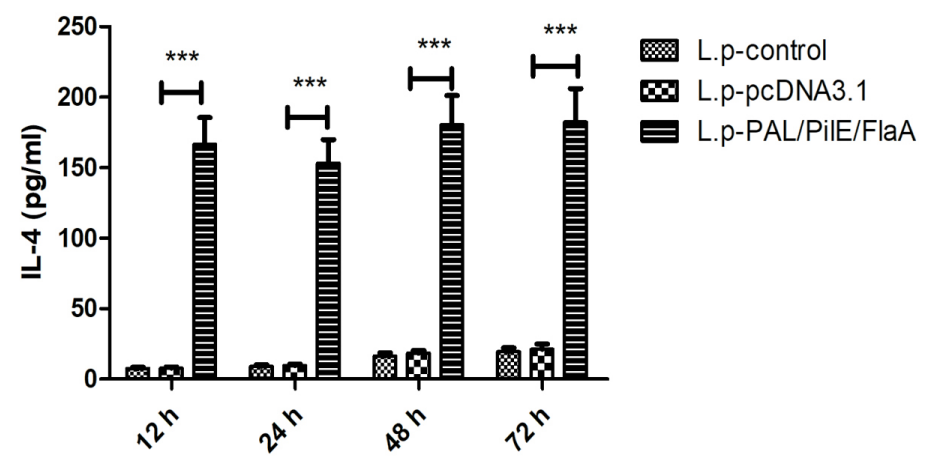

Figure 6

The production levels of cytokines form splenocytes extracted from mice at $16 \mathrm{~h}$ after a lethal challenge with Legionella pneumophila. Splenocytes were cultured and their supernatants were collected at 12, 24, 48, and $72 \mathrm{~h}$. The levels of TNF-a (A), IFNY (B), IL-12 (C), IL-4 (D), and IL-10 (E) were determined by ELISA kits. All data were expressed as mean $\pm S D(n=3) .{ }^{* \star *} P<0.001$ versus the L.p-pcDNA3.1 group. 


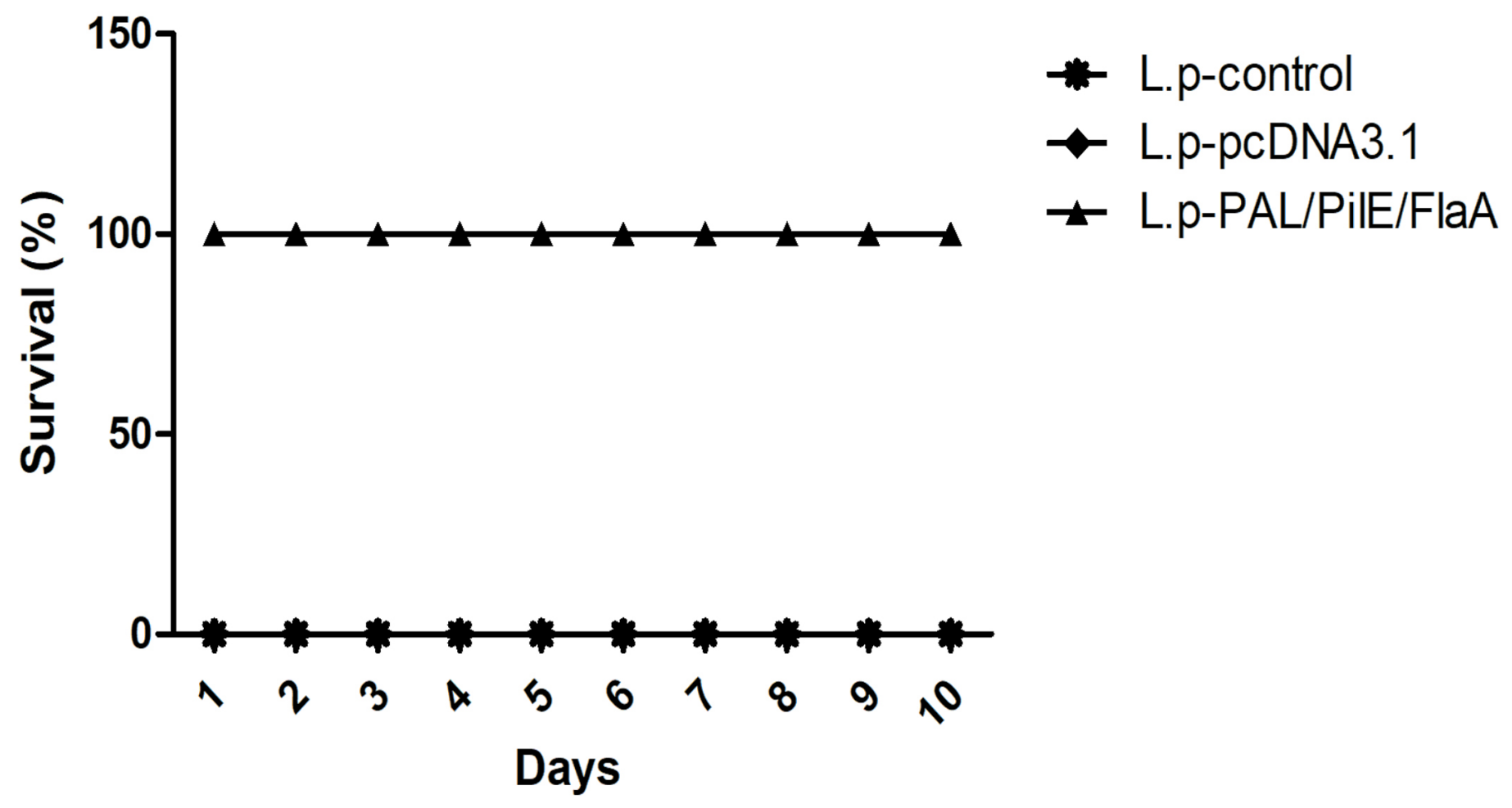

Figure 7

Protective immunity in mice after a lethal dose challenge with Legionella pneumophila. The survival rate of mice for 10 days after a lethal dose challenge with Legionella pneumophila was shown $(n=10)$.

\section{Supplementary Files}

This is a list of supplementary files associated with this preprint. Click to download.

- NC3RsARRIVEGuidelinesChecklist.pdf 